\title{
Educação Acessível: estéticas, corpos e deficiência ${ }^{1}$
}

\section{Petra Kuppers ${ }^{2}$ \\ Tradução: Gabriela Seger Camargo ${ }^{3}$ e Carla Vendramin ${ }^{4}$ \\ Resumo: \\ Abstract:}

Este artigo introduz o modelo social da deficiência aos professores de dança e discute as implicações dessa concepção sobre a deficiência para o ensino de dança, a apreciação da dança e da coreografia. A relação entre o dançarino de balé deficiente e o conceito do corpo dançante do balé é analisado como uma maneira de desafiar o entendimento sobre o corpo em estudantes de dança. $\mathrm{O}$ uso de estruturas e técnicas da dança-teatro são discutidas por meio do trabalho de performance de grupos de dança profissionais e comunitários de pessoas com e sem deficiência. A tese central deste artigo é que uma cultura de dança acessível não precisa somente de técnicas, espaços de trabalho, instalações de treinamento e palcos acessíveis, mas também de um trabalho educacional mais amplo no que se refere ao entendimento sobre a dança: a nossa capacidade de ler dança e apreciar a manipulação de corpos, no tempo e no espaço.

Plavras-chave: Modelo Social da Deficiência, Dança, Ensino da Dança, Coreografia.
This paper introduces dance teachers to the social model of disability, and discusses the implications of this conception of disability for the teaching of dance literacy, dance appreciation, and choreography. The relationship between the disabled ballet dancer and the concept of ballet's dancerly body is analysed as a way to challenge dance students' understanding of the body. The use of frames and other techniques of dancetheatre are discussed through the performance work of professional and community dance groups with and by disabled people. The core thesis of this paper is that an accessible dance culture needs not only accessible techniques, work spaces, training facilities and stages, but also wider educational work on the level of dance literacy; our ability to read danceand appreciate its manipulation of bodies, spaces and time. Key-words: Social Model of Disability, Dance, Dance teaching, Chorograp.

1 Artigo originalmente publicado em KUPPERS, Petra. Acessible Education: Aesthetics, body and disability. Research in Dance Education, vol. 1, ${ }^{\circ}$ 2, p. 119-131, 2000.

2 Professora do Departamento de Artes Contemporâneas, Manchester Metropolitan University. E-mail: aerfen@ aol.com

3 Bacharel em Letras e Tradutora. E-mail: keen.camargo@gmail.com@

$4 \quad$ Professora Assistente. Universidade Federal do Rio Grande do Sul. E-mail: carlavendramin@gmail.com 
Este artigo empreende a apresentação do modelo social da deficiência aos professores de dança e a discussão das implicações dessa concepção sobre a deficiência para o ensino da dança, da apreciação da dança e da coreografia. Particularmente, a relação entre o dançarino de balé com deficiência e o conceito do corpo dançante do balé é analisado como uma maneira de desafiar o entendimento dos estudantes de dança sobre o corpo. O termo corpo dançante se refere aqui aos conceitos naturalizados de fisicalidade adequados a técnicas de dança específicas. O artista com deficiência pode romper a expectativa convencional dos corpos na dança e pode oferecer novas maneiras de conceituá-los. Este artigo discute as performances de pessoas com deficiências físicas e de desenvolvimento. Nessas performances, as técnicas de dança-teatro oferecem pontos de ruptura e deslocamento, desafiando o seu público a reconceitualizar os corpos dançantes.

A tese central deste artigo é a de que uma cultura de dança acessível precisa não somente de técnicas, espaços de trabalho, instalações de treinamento e palcos acessíveis, mas também de um trabalho educacional mais amplo no que se refere ao entendimento da dança e da nossa capacidade de ler dança e de apreciar a manipulação de corpos, no tempo e no espaço.

O trabalho sobre o modelo social da deficiência apresenta reverberações para além da questão da deficiência, pois a deficiência se concentra na identidade como uma questão negociável no campo social e no corpo como o mensageiro principal de significado. Tradicionalmente, a identidade muitas vezes foi usada como um atributo fixo de um indivíduo. Teóricos como Butler (1994) propuseram maneiras alternativas de compreender a identidade social e o corpo, e se concentraram na função dos papéis e performances no campo social. Esta compreensão de identidade como negociação e performance já exerceu influência considerável na imagem de gênero e raça na dança, mas pode ser explorada de forma mais ampla na prática, seja no palco, nas salas de aula e nos contextos de comunidade. Desenvolvimentos recentes no sistema educacional britânico, como, por exemplo, o novo Currículo Nacional (1999), levam a sério o modelo social e suas implicações de acesso. No entanto, para que o ensino da dança seja realmente influenciado pelo modelo social, a estética da dança e as gerências do corpo precisam ser investigadas (LOMAS, 1998).

\section{O modelo social da deficiência}

Nós estruturamos a nossa compreensão sobre nós mesmos e sobre outras pessoas por meio do discurso: pelos modos de saber, pela categorização. Um discurso cincunscreve o que pode ser sabido sobre um assunto. A "deficiência" é uma construção discursiva, tal como gênero, raça ou sexualidade. O discurso é alterado historicamente, e novas maneiras de organizá-lo evoluem. Um exemplo disso é a mudança do ensino da história nas escolas britânicas: ela está mudando de um catálogo de "vitórias" para uma compreensão mais ampla sobre os "estilos de vida" (WILLIAMS, 1961, p. 57). Em vez de aprender apenas sobre batalhas e datas, os alunos britânicos agora aprendem sobre a vida cotidiana, a vida comum das pessoas em uma época diferente e são conscientizadas sobre a sua própria atividade de "olhar". É este tipo de "vivência" no ensino de história que permite a integração do material histórico dentro do currículo de dança, como é o caso dos pacotes de apoio educacional britânicos de agências de dança como o Cheshire Dance Workshop que produz diretrizes para o currículo de dança com temas como "Egito" e "os Tudors" (1997).

Assim como todo o conhecimento, é importante analisar e estar ciente sobre quem exatamente tem conhecimento sobre os outros, quem controla o acesso a esse conhecimento e quem o legitimiza como um campo de estudo adequado. Permanecendo com o exemplo de história, documentos sobre a vida cotidiana, a expressão subjetiva das vidas das classes trabalhadoras, comunidades étnicas e 
mulheres apenas recentemente foram relativamente compilados. Desde os anos 1960, um interesse sobre a história oral e a história comunitária tem levado à publicação de vários diários e biografias. Hoje, iniciativas como a transmissão de diários em vídeo e outros meios de registrar as existências locais, incluindo as apresentações locais no Domo do Milênio, e o projeto de Turnês de História da BBC de 2000, mudaram o que nós entendemos como um registro histórico: "a história vista de baixo" aumenta a extensão de vozes ouvidas, registradas e reproduzidas.

$\mathrm{Na}$ área de deficiência, o final do século XX testemunhou uma mudança de discurso local (principalmente anglo-americano), em parte trazida à tona pela atenção dada a vozes não dominantes e, em parte, pela intervenção local de pessoas com deficiência ativistas. O nosso conhecimento sobre o que "significa deficiência" está mudando, e isso se deve em grande parte, ao trabalho de acadêmicos e autores deficientes, como Linton (1998), Mairs (1996) Swain, Finklstein, French \& Oliver (1993). Esta alteração de percepção, uma mudança que descreverei aqui como de um modelo médico de deficiência para um modelo social, tem implicações para a prática artística, e para a maneira como ensinamos e aprendemos sobre o mundo social.

O modelo médico de deficiência ainda é dominante em várias áreas da vida social: ele descreve a deficiência como alojada dentro de uma pessoa. Na visão médica, a pessoa com deficiência é incapacitada pela sua condição física e intelectual específica. Esta condição é o foco do trabalho de médicos cientistas. A área dos estudos sobre a deficiência, no modelo médico, implica o conhecimento de cirurgia e outras formas de intervenção médica. O médico localiza o que é "uma aberração", o que é anormal no sistema do paciente e trabalha para normalizar a pessoa com deficiência ${ }^{1}$. $\mathrm{O}$ modelo médico levou a formas de intervenção médica como cirurgia cosmética para pessoas com Síndrome de Down, em uma tentativa de fazê-los parecer mais "normais". Do mesmo modo, este modelo levou a tentativas de muitos séculos para reprimir a linguagem de sinais em pessoas com deficiência auditiva, para que elas "falassem normalmente", mesmo que essa fala fosse "inferior" ao "normal" e potencialmente inadequado para as necessidades de comunicação da própria pessoa surda. A diferença física para o dominante tem sido reconhecida há tempo como "inferior". Este debate é consistente com as tentativas do século XIX de localizar a feminilidade, inferior à masculinidade dominante, em uma aberração física específica: o útero (a origem grega da palavra provocou a designação da doença amplamente reconhecida naquela época como histeria). Linguisticamente, e agora desacreditado, isso definia o status social da mulher como fraco e emocional, e medicamente vinculado a um órgão específico. Esse exemplo demonstra que a medicina não é neutra e que ela reflete as preocupações da sua época. O nosso conhecimento sobre corpos é moldado por, e molda, o discurso e o conhecimento de uma era.

Se o modelo médico localiza a deficiência na pessoa com deficiência e na sua aberração específica, o modelo social da deficiência altera radicalmente a mentalidade, os pontos de referência para o conhecimento. No modelo social, a deficiência é aparente na interação entre a pessoa com deficiência e o ambiente social. Uma pessoa apresenta uma deficiência como braços curtos, cegueira ou inabilidade de ler. É apenas quando essa forma particular de corporeificação encontra uma sociedade na qual braços longos, comunicação visual e palavra escrita são favorecidas, que a incapacidade se torna uma deficiência. Para uma mulher que utiliza uma cadeira de rodas, não é o seu corpo ou a cadeira de rodas, mas sim as escadas que a tornam incapaz. As barreiras da arquitetura inacessível, as barreiras de atitude moldadas historicamente para pessoas com deficiência e a discriminação institucional resultante são agora os fatores incapacitantes e não o corpo individual

1 Para uma discussão ampla sobre o estado de "normalidade" e deficiência ver Davis (1995) e para um panorama sobre a normalização e o seu uso nas políticas de deficiência, ver Fulcher (1996). 
de uma pessoa. Dentro destes termos, a deficiência se torna uma questão social e ambiental e não médica. Estudos sobre deficiência podem agora ser encontrados em departamentos de línguas, ciências sociais ou estudos culturais ${ }^{2}$. Como uma área de estudo, ela se preocupa com o significado da deficiência em uma cultura.

Pessoas com deficiência que atuam como ativistas adotaram a definição social de deficiência e a utilizaram para fazer campanha não para um tratamento "especial" - como a instituição médica ofereceu -, ou educação "especial", mas por direitos civis, ou seja, pelo direito de participar na sociedade em termos iguais. Esta exigência civil apenas pode ser atendida por meio de leis antidiscriminatórias, e não por meio de tentativas de normalizar as pessoas. Certamente ninguém esperaria hoje que uma pessoa negra branqueasse a sua pele ou utilizasse uma maquiagem pesada para fazer avanços em uma sociedade dominada por brancos, embora saibamos que a luta por igualdade racial está longe do fim. Tampouco uma pessoa com deficiência deveria ter que viver em termos de não deficiência, e se acomodar a uma definição de "norma" ditada por outra pessoa. Em vez disso, uma sociedade mais acessível, tanto em termos atitudinais e ambientais, erradicaria a deficiência como categoria significante, e deixaria apenas diversas diferenças à sua sombra.

O processo que levará a uma sociedade livre de barreiras para pessoas com diferenças e deficiências é longo e deve-se lutar por ele em frentes diferentes. Uma desses frentes é a das artes e da educação artística: precisamos desafiar e questionar o conhecimento que governa o modo como vemos o trabalho de arte, e analisar as normas que fundamentam os nossos conceitos de excelência artística. A educação em dança pode abraçar essa agenda social ao ensinar uma conscientização das normas físicas e de valores que fundamentam a dança nas suas formas históricas e em transformação. Na próxima seção, reviso a deficiência como portadora de significado na dança cênica.

\section{A dança da pessoa com deficiência e o corpo dançante do balé}

Na essência da dança está o corpo. Mais do que qualquer outra forma de arte, a dança depende da presença física e da expressividade. Essa confiança da dança no corpo estimulou a genealogia dos corpos "normativizados" exibidos no palco, corpos que refletem conhecimento social e categorizações específicas. Dentro dos estudos em dança, a relação histórica entre a dança e o corpo aristocrático recebeu atenção de autores como Franko, (1993) e Foster (1986) e apresenta o alinhamento da dança com as dinâmicas de poder do patriarcado (Adair, 1992) e da heterossexualidade normativa (Burt, 1995; Kuppers, 1998). Corpos específicos são ou posicionados como "centrais" como nas danças de corte, ou de outras formas apontam, para além do inferior e do humilde, para um corpo "elevado" e disciplinado.

A dança em si não é um campo unificado; existem muitas formas de dança diferentes, tanto sincronicamente, dentro da paisagem cultural atual, quanto diacronicamente, ao longo da história da dança. Em seus estudos sobre a Dança Americana, Foster (1986) demonstra que técnicas diferentes treinam e exigem corpos dançantes diferentes, além de públicos afinados de maneiras diferentes. Foster (1986) mostra as diferenças nos corpos dos dançarinos e nas exigências dos espectadores exemplificadas no trabalho de Deborah Hay, George Balanchine, Martha Graham e Merce Cunningham. Existem muito mais escolas de dança que exigem corpos treinados especificamente e públicos afinados com essas especificidades ${ }^{3}$.

\footnotetext{
2 Ver, por exemplo, o programa de Doutorado em Estudos sobre deficiência da Universidade de Illinois em Chicago

$3 \quad$ Ver também Cohen Bull (1997).
} 
De modo algum tudo isso depende de uma distinção hierárquica entre os corpos habilidosos de artistas e os corpos amadores dos espectadores. No entanto, nesta seção, eu me concentro no balé e na sua forma particular do corpo dançante, o corpo moldado por discursos e regimes de uma forma de dança específica, seu programa de treinamento e sua posição cultural.

O balé e a sua imagética podem ainda ser vistos, discutivelmente, como a imagem cultural principal na cultura Ocidental, mesmo que esse bastião seja desafiado pela cobertura generalizada de formas contemporâneas de dança na mídia popular. Uma pesquisa rápida e geral com dançarinos internacionais e autores de informações biográficas sobre dança mostra que geralmente, o balé, e especificamente a bailarina capturaram inicialmente a sua imaginação e os afinaram para dança (Aalten, 1997).

Esta visibilidade cultural do balé como um conceito genérico de dançar também se mostra nos estudos etnográficos de jovens dançarinos e seus mundos conceituais:

Quando eu questionei [os membros de um Grupo de dança de jovens] se eles tinham um dançarino preferido, descobri que Baryshnikov e Nureyev eram mencionados com mais frequência, embora somente Trisha [uma das entrevistadas] tenha expressado uma preferência e amor pelo balé clássico (THOMAS, 1993, p. 80).

No âmbito da dança cênica, o balé é o mais proximamente alinhado com o conceito de um corpo dançante altamente específico. O conceito social - e coreográfico - de perfeição, focado nas realizações do dançarino de balé como um ícone cultural, pode ser questionado de modo fecundo pela atenção cuidadosa às diferenças específicas que outros corpos e o seu uso do espaço podem representar para a estética do balé. A seguir, apresento o relacionamento entre corpos perfeitos, estética do balé e o encontro entre dança e deficiência com referência a uma série de exemplos a partir de vários aspectos da cultura popular. Eu os utilizo em sala de aula para levantar discussões sobre os "corpos dançantes" que ganham vida.

Dançarinos cadeirantes são uma subseção específica de dançarinos com deficiência profissionais nos gêneros moderno e clássico, que ganharam visibilidade pública por meio de grupos como CandoCo, Cleveland Balé Dancing Wheels ou Axis. Em relação à escolha dos grupos pelo balé como sua técnica principal, dois aspectos do balé são de interesse particular: a bidimensionalidade e a negação do peso.

Acadêmicos e pesquisadores em dança criticaram o ideal da bidimensionalidade no balé: "o balé clássico compactuou com a preservação do corpo clássico, enfatizando o compromisso com a linha, a falta de peso, a elevação e a extensão e presença etérea em vez de uma corporalidade real". (WOLFF, 1997, p. 95) ${ }^{4}$.

No balé, o ímpeto é em direção à linha, e a clareza da frontalidade, como evidenciado pelo foco do balé na abertura, um alinhamento dos pés não em paralelo, mas em um formato de $V$, apontando para os lados, que necessita que a articulação do quadril seja rotada para fora. Dançarinos que são tecnicamente bons, mas que não apresentam o corpo necessariamente flexível são recusados em escolas de dança (AALTEN, 1997).

A outra exigência do corpo no balé é a negação do peso. É um aspecto da técnica do balé:

Os dançarinos são vistos como artistas que desafiaram com sucesso as leis da gravidade. Isso não é somente uma consequência do gosto e da moda na época da

$4 \quad$ Para outras discussões ver também Dempster (1999). 
sua origem, mas também uma característica específica da técnica do balé. No balé, o centro do movimento é a coluna. Um dançarino sempre mantém o seu corpo elevado, deixando os braços e as pernas realizarem a maior parte do trabalho. O movimento básico no balé é ascendente (AALTEN, 1997, p. 47).

O peso e a sua negociação também são aspectos da indústria e das imagens populares do balé. As biografias de dançarinas como a de Kirkland (1986) evidenciam a necessidade das dançarinas de se conformarem a uma estética de desaparecimento: a anorexia e outros distúrbios alimentares são associados Ao balé. A atenção dada a esses problemas de "sucesso feminino" especificamente nos anos 1980 e 90 elevaram os distúrbios alimentares ao status de mito, ao aspecto esperado da cultura física feminina. Na sala de aula, eu acho útil comparar as discussões correntes sobre as modelos femininas em revistas femininas, filmes sobre ginastas como "Perfect Body"5 , discussões sobre disciplinas físicas de concursos de beleza infantis, assim como histórias pessoais dos estudantes para analisar este conjunto de espetáculo, repugnância, fascinação e disciplina na imagem feminina contemporânea ${ }^{6}$.

O legado do balé, aliado a sonhos impossíveis de meninas, demonstra que as bailarinas de hoje ainda são forçadas a comentar sobre a sua saúde e as suas práticas alimentares em entrevistas para a televisão ou para a imprensa popular. Isso é comprovado pela imagem pública da estrela europeia Sylvie Guillem e da primeira bailarina do Royal Balé, Darcey Bussel.

Essas questões de ausência de peso e negociação visual de esforço muscular no balé também levam a interessantes discussões sobre a relação entre habilidade, força e masculinidade na figura do bailarino homem. Formas culturais populares negociam essas questões. Este é o caso de filmes sobre ícones masculinos do balé, como "White Nights" 7, e de um pôster de uma campanha publicitária britânica para um cereal matinal, no qual um casal de bailarinos aparece em uma posição que sugere que a mulher está levantando o homem, o que conota força feminina. Ao mesmo tempo, no entanto, a imagem sutilmente mostra a (suposta) impossibilidade física deste ato nestas poses específicas. A piada visual decorre da inversão de papéis entre os dançarinos masculino e feminino, lidos em relação à falta de esforço e de peso do balé.

Mas mesmo se descontarmos os relatos amplamente difundidos e exagerados sobre regimes de alimentação de dançarinos e nos concentrarmos na prática material da dança e da apresentação, os balés por si mesmos fornecem materiais adequados para comprovar a insistência da forma em leveza e imaterialidade.

O exemplo mais frequentemente citado da tendência do balé voltada para a evanescência, para a negação da presença física, é o balé Giselle (1841) no qual uma mulher morre e retorna como uma wili, uma fada, um ser insubstancial e leve. Em outros balés, tanto homens quanto mulheres dançam os papéis de pássaros, competindo entre si na execução de voo. Em termos de técnica, o balé enfatiza a ausência de peso da bailarina e a fisicalidade que desafia a gravidade do bailarino pela confiança em levantamentos e saltos frequentes.

Essa imaterialidade do balé coloca-se em contraste com a hipervisibilidade do corpo deficiente. Como os estudos sobre deficiência demonstraram, a "deficiência" rotula um indivíduo: ela se torna signo principal da identidade, ofuscando todas as outras. Portanto, o salto do balé é negado ao artista com deficiência, que nunca é "apenas" um supostamente genérico artista.

Albright (1997) discute o uso da estética do balé por bailarinos com deficiência e vê o seu 5 Direção de Douglas Barr, Estados Unidos, 1997.

6 Ver também BORDO (1993).

7 Direção de Taylor Hackford, 1985. 
fracasso em retratar uma imagem empoderada sobre a deficiência. A sua crítica está focada na relativamente inquestionável aceitação dos estereótipos de balé nos trabalhos de grupos dos EUA como o Cleveland Balé Dancing Wheels ou Light Motion.

Embora [eles] estejam produzindo trabalhos que não escondem a deficiência, mas sim utilizam a diferença de capacidades físicas para criar coreografias novas e criativas, eu sinto que muito do seu trabalho é ainda informado por um ethos que restaura o corpo clássico dentro do corpo deficiente. Mesmo que corporificados de formas diferentes, os conceitos de graça, velocidade, força, agilidade e controle ainda estruturam a estética dessas companhias. Logo, [...] na minha opinião, eles não desconstruíram completamente o privilégio da capacidade dentro da dança (ALBRIGHT, 1997, pp. 83-4).

Os grupos discutidos, de fato, mostram os usuários de cadeira de rodas dentro de cenários baléticos. Em discussões com os estudantes, descobri que é bastante proveitoso deixá-los pensarem sobre quais características, em relação aos movimentos e às coreografias realizadas por dançarinos deficientes, transmitem uma "sensação" balética. Por meio deste apelo ao nosso ensino cultural, um aspecto essencial da estética do balé - e de outras formas de dança - pode ser levantado e discutido.

Mesmo que o dançarino, usando uma cadeira de rodas, rompa com a bidimensionalidade naturalizada do corpo balético, ao se estender para trás e para frente além de lateralmente no espaço, este volume bidimensional pode ser recuperado pela ênfase em um tipo diferente de geometria. Logo, as linhas ao longo dos braços e dos ombros são enfatizadas, os dançarinos não deficientes, desenhando essas linhas, prolongam o alcance do dançarino com deficiência pelo espaço (um equivalente ao levantamento balético); ou as rodas da cadeira permitem que o dançarino deslize sem esforço em uma linha reta pelo espaço.

Apontar para a destituição do corpo físico e para a euforia que acompanha o espírito controlador é totalmente apropriado no contexto da estética do balé; desconstruir essas imagens é desconstruir a estética do balé como tal. O pareamento de capacidade e deficiência na crítica de Albright (1997) é, na minha opinião, uma falsa dicotomia. A "capacidade" no balé é sempre inumana, não física. $\mathrm{O}$ "verdadeiro dançarino" de balé é a sílfide, insubstancial, leve. A ambivalente descrição da bailarina perfeita, feita por Foster (1995), vê a sua morte no momento da perfeição:

[...] na pose de Paloma Herrera testemunhamos a morte do corpo. Nós vemos estase, a doação perfeita da vitalidade física para a pureza formal. Podemos sentir o corpo arrebatado no final do seu esforço completo. Podemos ouvir o silêncio do estado em que o corpo fundiu-se com a geometria... E então, miraculosamente, o corpo dançante se reaviva... O balé, uma celebração desta dança com morte, se alterna entre a fixação do modelo do corpo e o momentum da vitalidade física necessária para motivar o corpo por esses modelos (p. 112).

Como Aalten (1997), Foster (1995) possibilita leituras potencialmente positivas da tendência de negação à vida, presente no balé. No entanto, para mim, o resultado ainda é uma ênfase exagerada na futilidade da negação do corpo.

Cadeirantes são incapacitadas pelas suas extensões mecânicas e físicas, mas a sua luta é mais por quantidade do que qualidade, considerando que as dançarinas não deficientes também 
lutam com peso, configuração de quadril e desenvolvimento de seios. O corpo ainda está preso a estereótipos culturais. Mas algumas dessas lutas são relativamente invisíveis: os dançarinos de balé não deficientes ainda mantêm regimes, exigências, dietas e lesões decorrentes da técnica de dança. A diferença do ideal é normalizada, é tornada culturalmente invisível, os seus esforços são ocultos. Quando dançarinos deficientes entraram neste campo caracterizados por lutas com fisicalidade, o seu alinhamento com o "corpo preso", a narrativa deficiente da tragédia, restrição e sofrimento, tornou-os alvo da crítica de dança tradicional ${ }^{8}$. Mas as narrativas são desafiadas: a presença contínua de grupos de balé cadeirantes como o Cleveland Balé Dancing Wheels e o Light Motion, inserem na cultura um novo corpo dançante, lentamente, pouco a pouco, por repetição. As bolhas, as distensões, o suor e as ataduras de bailarinos sem deficiência são convencionalmente sublimadas sob a estética do balé, e se tornam invisíveis. A presença do dançarino deficiente pode tornar todos os desvios da norma do balé mais visíveis, desafiando o mito da proximidade relativa do dançarino não deficiente ao ideal. Assim, o dançarino deficiente amplia a sua carga de "visibilidade" em relação a outros corpos ao seu redor, cada um na sua diferença específica, na sua incorporação específica diante das linhas ideais do balé. Para o aluno com deficiência, a reavaliação da estética do balé pela insistência na diferença como um elemento positivo da coreografia pode ser uma experiência empoderadora. Da mesma forma, um aluno sem deficiência pode usar a presença hipermarcada do corpo deficiente do seu ou da sua aluna como um lembrete das diferenças culturalmente não marcadas. As maneiras específicas de estender a linha, ou de criar simetrias específicas ao corpo de cada dançarino podem fornecer caminhos empolgantes para coreografias de balé.

\section{Dança-teatro - Aprendendo a ver de maneira diferente}

O dançarino com deficiência pode trazer percepções valiosas para o funcionamento e para o potencial do domínio do corpo ideal do balé. Mas os dançarinos com deficiência também abriram outros espaços em trabalhos de dança. Se boa parte das danças de pessoas com deficiência "normaliza" o corpo deficiente na estética dominante da dança, outras formas de performance realizadas por pessoas com deficiência desafiam mais profundamente os significados da deficiência. Elas se alinham com o modelo social de deficiência, e portanto exigem que o público não seja levado a "ver para além da deficiência", mas em vez disso, reconheça a sua construção social. Este tipo de performance localiza a experiência incapacitante ou deficiente no encontro do performer-espectador, e não no corpo deficiente. A dança-teatro é uma dança cênica cuja estética enfatiza as inter-relações entre as formas de saber, o público ativo e o performer provocativo. A seguir, demonstro como o modelo social da deficiência foi articulado à dança por pessoas com deficiência em uma variedade de configurações, pela implementação das técnicas da dança-teatro. Concentro-me especificamente em um mecanismo particular da dança-teatro: o distanciamento do público e do performer pelo enquadramento.

O quadro da dança-teatro movimenta corpos, ações e movimentos fora do seu significado cotidiano e permite que os vejamos de maneira diferente. Ao fazer isso, os artistas podem demonstrar a natureza construída do cotidiano, as pressuposições que o espectador traz para uma imagem, uma performance. Nos exemplos a seguir, os dançarinos com deficiência utilizaram dispositivos de enquadramento para desnaturalizar as suas performances, para mostrar como a construção de deficiência, não a incapacidade em si, fixa o corpo deficiente. As estratégias de performances e de coreografias discutidas aqui foram analisadas fecundamente em sessões de análise de dança e ampliaram de maneira útil o trabalho de apreciação de dança em sessões de dança comunitária. 
Em 1997, Magpie, uma companhia com dançarinos com deficiência, e a Retina Dance Company criaram uma performance, para o festival Blitz 97 em Londres. O trabalho físico por si só lidava dramaticamente com estereótipos ou com pressuposições de que os membros da companhia com dificuldades de aprendizagem encontram nas suas vidas, mas a performance enfatiza fortemente estas experiências como o quadro do trabalho:

Realizada no alto da Área de Exposição do $5^{\circ}$ andar em South Bank, este trabalho de site-specific convidou o público, pela primeira vez, a ficar de fora e olhar pelas janelas. Quanto mais isolados e desconfortáveis os membros do públicos se sentiam, melhor. Afinal, como ambas as companhias apontam, é apenas uma representação da maneira como aqueles com deficiência intelectual frequentemente se sentem, como estranhos olhando de fora para a sociedade (COWL, 1997, p. 16).

As companhias empregam limitações físicas espaciais para transmitir um aspecto da experiência sobre a deficiência. Eles não usam exercícios de simulação, exercícios destinados a dar às pessoas sem deficiências um "gosto" sobre a deficiência, uma prática muito criticada por ativistas com deficiência. Esses ativistas apontam para o fato de que a deficiência significa muito mais do que incapacidade, e que a simulação não leva em conta nem o treinamento, nem os hábitos que as pessoas com deficiência desenvolvem a partir de seus corpos específicos. Em vez disso, o enquadramento físico é usado para apontar para o enquadramento conceitual ao qual estão sujeitas as pessoas com deficiência em nossa cultura, ou seja, a prisão metafórica, elaborada por nossos pressupostos e conhecimentos presumidos sobre a deficiência, que confina as pessoas tidas como deficientes. Isso aponta para a dimensão social da deficiência, a criação da deficiência no encontro entre as pessoas, entre seus sistemas de valores, e a expressão desses valores nas instituições com as quais convivemos.

O grupo de artistas vienense Bilderwerfer também desafia as imagens e significados dominantes do corpo deficiente na cultura, através de performances que utilizam telas e quadros para destacar o ato de ler a dança. O Bilderwerfer emprega treinamento em contato improvisação com sua ênfase no peso e espaço, a fim de trabalhar uma formação em dança acessível para pessoas com deficiências físicas e de desenvolvimento.

Em sua performance Einblicke (1995), a companhia se apresentou em uma vitrine de uma galeria comercial, atrás do vidro, para o público sentado e passante na área de transeuntes de Viena. Textos e música foram canalizados para o público por meio de alto-falantes, a presença "natural do corpo na dança foi rompida através desses mecanismos de distanciamento. A coreografia trabalhou com noções de privacidade e recusa de exibição. Em uma parte da performance, a dançarina Elisabeth Löffler criou um arranjo vívido e elaborado no espaço com o seu corpo no chão, a sua cadeira de rodas e as suas muletas justapostas e alinhadas entre si, enfatizando as formas e os caminhos. Nenhuma narrativa clara emergiu para um público para quem a cadeira de rodas e as muletas frequentemente significam restrições e tragédia, e não alcance e jogo. Em vez de fornecer uma nova narrativa que mostra o dançarino com deficiência como feliz com a sua incapacidade, Löffler negou qualquer leitura emocional para o seu estudo do movimento. Ela não fez contato com o seu público, nem olhou para ele, ou sorriu. Combinada com os enquadramentos de desestabilização, a performance tinha como objetivo perturbar o público, perturbar ideias fixas sobre os significados da deficiência e da dança. Na coreografia de Einblicke, o corpo deficiente emergiu como diferente, mas ainda não categorizado. Ele emergiu como um corpo não conformado com o significado social da deficiência, nem com os significados sociais do discurso de dança popular dominante, o balé, com os seus corpos eretos e exposição frontal. Os dispositivos de enquadramento da dança-teatro, que possibilitaram realizar a performance em um ambiente não familiar, em uma linguagem de dança ou 
estética não familiar, na qual os dançarinos foram colocados atrás de um vidro e os sons mediados por alto-falantes, podem ser vistos como algo que perturba o espectador. O enquadramento sabota as conotações naturais que a dança apresenta na nossa cultura e, favorecendo um certo distanciamento do espectador, permite que se mostre os corpos em construção na cena.

\section{Levantando questões: a leitura da dança, dos enquadramentos e dos discursos.}

Nos dois exemplos de performances de pessoas com deficiência, as estratégias estéticas solicitam que o espectador torne-se consciente de si mesmo. Essas performances o fazem por meio de recursos coreográficos, os quais dividem o espaço entre o público e o performer, desnaturalizando o encontro tradicional na performance, que é caracterizado por divisões implícitas, para ressaltar as divisões explícitas e os territórios desconhecidos. As duas coreografias empregam momentos de diferença em relação às performances tradicionais, na esperança de que este estranhamento provocado pela performance influencie outros aspectos da leitura da dança pelo público ${ }^{9}$. Discutir estas e outras performances levantou questões interessantes para alunos que repetidamente eram solicitados a examinar os seus próprios pressupostos sobre a maneira certa de fazer e apresentar dança. Por meio dessas discussões, os alunos aprenderam a compreender a dança não apenas como uma manipulação do corpo no tempo e no espaço, mas também como uma manipulação do conceito de corpo no seu enquadramento de "normalidade”, saúde", "integridade", "inteligência”, "controle" e "arte". Nestes trabalhos discutidos por Magpie, Retina Dance e Bilderwerfer, uma análise do evento de dança precisa levar em consideração a colocação do público, a maneira como o público é abordado, as manipulações das expectativas e as maneiras como a diferença é comunicada e apresentada.

Ao estudar essas performances, eu solicitei aos alunos que articulassem os seus sentimentos sobre o trabalho, e muitos revelaram uma sensação de inquietação e mesmo irritação. Eles não tinham certeza sobre como lidar com essas danças, como trabalhar com as estruturas estéticas com as quais estavam acostumados a ver na dança, dentro de situações que apresentavam a eles pessoas percebidas por alguns como infelizes, trágicas, feias ou tristes. As emoções e os significados trazidos do conceito de deficiência se interpuseram na apreciação da dança. Na sala de aula, nós não estávamos tentando acobertar as reações emocionais que surgiram em relação aos dançarinos e à performance. Em vez disso, olhávamos em detalhe para as origens desses sentimentos, para o nosso entendimento social e o conhecimento sobre a deficiência e para a maneira como os artistas trabalhavam com as imagens que seus corpos conotavam aos espectadores. No nosso trabalho analítico na sala de aula, ficou claro que não estávamos reagindo somente ao arranjo abstrato de corpos no espaço e no tempo, mas aos corpos em si e à sua colocação no discurso social.

O ensino da análise de dança amplia-se para o ensino sobre corpos e significados sociais e sobre reações emocionais condicionadas por esses significados. Ou seja, sobre os discursos da fisicalidade. A coreografia de pessoas com deficiência pode ser fortalecida por essa colisão de significados, e por ideias de desafio e risco. Logo, ambas as performances discutidas anteriormente

9 Essas esperanças de romper com as pressuposições das pessoas nem sempre são cumpridas: após as apresentações de Viena, algumas pessoas telefonaram para reclamar sobre o "uso" de pessoas com deficiência como espetáculo. Para esses membros do público (ou transeuntes), o afastamento das pressuposições culturais de pessoas com deficiência como passivas não ocorreu na apresentação. Talvez ela tenha ocorrido quando eles são informados sobre o fato de essas pessoas serem artistas, ou quando eles leem resenhas nos jornais, ou sobre o seu financiamento anual por autoridades das artes. A performance do Bilderwerfer como uma intervenção nos significados da deficiência ainda está em andamento. 
enfatizam a dissociação e a dissonância. Isso ocorre por meio de barreiras físicas colocadas entre os espectadores e o público, por meio da ruptura da ligação natural entre voz e corpo no palco, ou por meio de uma ênfase na privacidade. Novas formas de presença física e beleza podem ser encontradas, mas o público, com frequência, tem de trabalhar em si mesmo para ser capaz de vê-las. O público pode ser seduzido para ver, conduzido pela fascinação do macabro ou do exótico. Por exemplo, quando Löffler torna as suas muletas "estranhas" ao manipulá-las como brinquedos sexuais, ela conota aspectos de outra zona proibida. De que forma a manipulação das muletas e da cadeira de rodas de Löffler são diferentes de uma investigação de um dançarino sobre a sua relação com o chão ou com o alinhamento de seu corpo com estruturas definidas? Löffler está movendo livremente seu corpo com deficiência, restrito ou trágico, ou está movendo nossas pressuposições sobre o corpo dela?

Após analisar essas performances na sala de aula, descobri que é muito interessante retornar para a dança de corpos não deficientes e observar como a apreciação dos alunos da dança mudou, a partir do momento em que seus corpos perdem a sua "naturalidade". As análises dos alunos ganharam profundidade conforme eles se tornaram conscientes dos mecanismos do corpo dançante na sua relação com a técnica, o significado social e as codificações emocionais.

Analisar as estratégias de performance e os dispositivos coreográficos utilizados por artistas com deficiência com os alunos significa estimular um ensino em dança que é consciente da completa coreografia da dança nos encontros físicos e culturais dos corpos. Essa atenção à estética da dança e à deficiência pode suscitar uma cultura de dança acessível. A acessibilidade não se refere somente às alterações de incapacidades específicas para o encontro com a performance "normal", mas ao fornecimento de espaço conceitual para um distanciamento que favoreça uma observação das nossas estruturas culturais. Uma cultura de dança acessível não é exclusiva, não condenará certas técnicas e celebrará outras. Ao contrário, ela vê todas as danças e todas as técnicas como fundamentadas em seu corpo dançante específico e em sua abordagem do público, e não elevará o ideal de uma forma de dança à dominância cultural para que esse ideal se torne uma ferramenta de medição. Logo, uma análise da deficiência como construção social e ponto de partida empolgante para novas explorações de alinhamentos do espaço e corpos pode ser empregada de forma útil para ampliar o entendimento dos alunos dos seus próprios corpos específicos e regimes, e seus posicionamentos nas nossas cultura compartilhada. O trabalho de companhias com artistas deficientes como a Bilderwerfer, Magpie, Retina Dance Company, CandoCo, Blue Eyed Soul, Axis, Cleveland Balé Dancing Wheels ou Light Motion podem realçar a nossa compreensão da diversidade da corporeidade. Elas podem fazer isso não apenas adicionando a diferença à norma, mas também nutrindo os desenvolvimentos das comunicações de dança com corpos, reinventando centros, normalidades, formas de ver e de fazer e mantendo a dança viva.

\section{Referências}

AALTEN, A. Performing the Body, Creating Culture. In: K. DAVIS (Ed.) Embodied Practices: Feminist Perspectives on the Body. London, Thousand Oaks, New Delhi: Sage, 1997. p. 41-58.

ADAIR, C. Woman and Dance: sylphs and sirens. Houndsmill, Basingstoke: Macmillan, 1992.

ALBRIGHT, A. C. Choreographing Difference: the body and identity in contemporary dance. Hanover and London: Wesleyan University Press, 1997.

BORDO, S. Unbearable Weight: feminism, Western culture, and the body. Berkeley, Los Angeles, London: University of California Press, 1993. 
BURT, R. The Male Dancer: bodies, spectacle, sexualities. London and New York: Routledge,1995

BUTLER, J. Bodies that Matter. London and New York: Routledge, 1994.

CHESHIRE DANCE WORKSHOP. Guidelines for Curriculum Dance: Resource pack. Winsford: CDW, 1997.

COHEN BULL, C. J. Sense, Meaning and Perception in Three Dance Cultures. In: J.DESMOND (Ed.) Meaning in Motion. Durham and London: Duke University Press, 1997.

COWL, C. Small Fish. Animated (Autumn), 1997, p. 16-17.

CROCE, A. Discussing the Undiscussable. The New Yorker, 26 dez-2 jan, 1994/5, p. 54-60.

DAVIS, L. J. Enforcing Normalcy: disability, deafness, and the body London: Verso, 1995.

DEMPSTER, E. Women Writing the Body: let's watch a little how she dances. In: A. CARTER (Ed.) The Routledge Dance Studies Reader. London, New York: Routledge, 1999.

DEPARTMENT FOR EDUCATION AND EMPLOYMENT (DfEE). The National Curriculum (DfEE/ QCA), 1999.

FOSTER, S.L. Reading Dancing. Bodies and Subjects in Contemporary American Dance. Berkeley, Los Angeles, London: University of California Press, 1986.

FOSTER, S.L. Harder, Faster, Longer, Higher: A Post-Modern Inquiry into the Ballerina's Making. In Bordertensions: dance and discourse. Proceedings of the Fifth Study of Dance Conference. Department of Dance Studies, University of Surrey, UK, 1995.

FRANKO, M. Dance as Text: ideologies of the baroque body. Cambridge: Cambridge University Press, 1993.

FULCHER, G. Beyond Normalization but not Utopia. In L. BARTON (Ed.) Disability and Society: emerging issues and insights. London and New York: Longmanpp, 1996, p. 167-190.

KIRKLAND, G. Dancing on my Grave. Doubleday Press, US, 1986.

KUPPERS, P. Vanishing in Your Face: Embodiment and Representation in Lesbian Dance Performance. Journal of Lesbian Studies, 2/3, p. 47-63,1998.

KUPPERS, P. Performativity and the Disabled Dancer. In: Choreographic Politics. Congress on Research in Dance Proceedings. Los Angeles: Congress on Research in Dance, 1999, p. 131-138.

LINTON, S. Claiming Disability. Knowledge and Identity. New York and London: New York University Press, 1998.

LOMAS, C. Art and the Community: Breaking the Aesthetic of Disempowerment. In: Dance, Power, and Difference: critical and feminist perspectives on dance education, Champaign: Human Kineticspp, 1998, p. 148-169.

MAIRS, N. Waist-High in the World: a life among the nondisabled Boston: Beacon Press, 1996.

MARTIN, C. High Critics/Low Art. In: G. MORRIS (Ed.) Moving Worlds. Re-writing dance. London, 
New York: Routledge, 1996, p. 320-333.

SWAIN, J., FINKELSTEIN, V., FRENCH, S. \& OLIVER, M. Disabling Barriers - Enabling Environments.London, Thousand Oaks, New Delhi; Sage, 1993.

THOMAS, H. An-Other Voice: young women dancing and talking. In H. THOMAS (Ed.). Dance, Gender and Culture. Houndsmill, Basingstoke: London, 1993.

WILLIAMS, R. The Long Revolution. Harmondsworth: Penguin, 1961.

WOLFF, J. Reinstating Corporeality: feminism and body politics, in: J. DESMOND (Ed.) Meaning in Motion. Durham and London: Duke University Press, 1997. 